\title{
Real-life use of long-acting antimuscarinic agents following their approval for COPD treatment
}

To the Editor:

Chronic obstructive pulmonary disease (COPD) pharmacological treatment aims to reduce symptoms, represented mostly by dyspnoea and its impact on daily life, and future risk, i.e. lung function decline, mortality and exacerbations [1]. Inhaled therapies, including long-acting bronchodilators (LABD) and inhaled corticosteroids (ICS), are the main treatments recommended for COPD patients. LABD have been found not only to improve lung function, decrease dyspnoea, increase exercise tolerance and improve health status, but also to reduce the rate of exacerbations. In that respect, some studies suggested that long-acting antimuscarinic agents (LAMA) could be more effective than long-acting $\beta_{2}$-agonists (LABA) [2]. In most countries, ICS are indicated only as part of fixed-dose combinations (FDC) with LABA and are used mostly to decrease the risk of exacerbations, which is associated with health status improvement [3]. Therefore, it appeared logical to restrict their use to patients at high risk of exacerbations. The long-term benefit of combining LAMA and FDC (triple therapy) is not strongly documented [4].

Many studies in various countries found discrepancies between guidelines and real-life practice regarding long-term maintenance treatment in patients with COPD [5-7]. Although the impact of nonadherence to guidelines on efficacy outcomes is controversial [8], it increases healthcare costs [9] and, therefore, decreases cost-effectiveness. In addition, side-effects might be an issue for some treatments. For instance, ICS may increase the risk of pneumonia and induce clinically detrimental systemic side-effects in the long term [10], suggesting that overuse outside recommended indications might be associated with a decreased benefit-risk ratio.

Many new treatments for COPD have been recently released or are about to be launched [11-14]. They include mostly new LABD, ICS and various combinations of these agents. Therefore, it appears important to understand better how the release of new treatments impacts treatment decisions. The major challenge here is to rationalise physicians' prescription behaviours and improve adherence to guidelines.

The present study was designed to assess how the release of tiotropium on the French COPD market (June 1, 2006) influenced treatment patterns among respiratory physicians. As per June 20, 2012, the multicentre French Initiatives BPCO cohort had recruited 846 COPD outpatients from 17 hospitals, 421 from May 2002 to May 31, 2006 (period 1, before tiotropium release) and 425 from June 1, 2006 to June 20, 2012 (period 2, with tiotropium available). The date of June 20, 2012 was chosen for two reasons: 1) to obtain a comparable number of patients in period 2 and period 1; and 2) to avoid contamination by the appearance of newer products on the market (e.g. indacaterol). Table 1 compares selected clinical characteristics and patterns of inhaled therapy between the two periods.

Overall, the period 2 population was slightly younger, comprised of a higher proportion of women, and was characterised by significantly less severe airflow obstruction and numerically less severe quality of life impairment. Dyspnoea and exacerbations during the previous year were similar between the two populations. Tiotropium use increased markedly from $4 \%$ (clinical trial patients) in period 1 to $53 \%$ in period 2. Tiotropium was prescribed mostly (63\%) in association with FDC, with $32.5 \%$ of patients receiving triple therapy overall. Furthermore, the proportion of patients receiving triple therapy was far from negligible in patients with mild and moderate airflow obstruction (9.8\% and 26.5\%, respectively), although these figures remained lower than in patients with severe and very severe airflow obstruction (38.2\% and $59.6 \%$, respectively). It was a surprise to observe a low proportion of patients being treated with bronchodilators only, even during period 2 (23.4\%). Finally, although the overall proportion of patients on FDC remained perfectly identical throughout the studied periods (56.5\%), over half of patients on FDC during period 2 received triple therapy (57.5\%).

These data illustrate that the release of a new class of treatment, namely LAMA, resulted in a noticeable increase in overall treatment intensity, with relatively low usage of this treatment outside FDC. This could not be explained by an increased severity of COPD patients in period 2, as patients included during this period actually exhibited less severe COPD than those recruited in period 1 . 
TABLE 1 Comparison of patient and treatment characteristics between periods preceding and following the release of tiotropium

\begin{tabular}{|c|c|c|c|}
\hline & Period $1^{\#}$ & Period $2^{\pi}$ & p-value \\
\hline \multicolumn{4}{|l|}{ Patient characteristics } \\
\hline Patients n & 421 & 425 & \\
\hline Age years & 65 (58-73) & $64(57-72)$ & 0.04 \\
\hline Smoking history pack-years & $40(26-57)$ & $40(24-57)$ & 0.99 \\
\hline Females $\%$ & 19 & 26 & 0.01 \\
\hline $\mathrm{FEV}_{1} \%$ predicted & $48.1(33.6-65.4)$ & $54.0(38.0-69.4)$ & 0.001 \\
\hline GOLD grade $3-4 \%$ & 53 & 45 & 0.02 \\
\hline Exacerbations per patient per year ${ }^{+}$ & $1.0(0-3.0)$ & $1.0(0-2.0)$ & 0.06 \\
\hline mMRC dyspnoea grade & $2.0(1.0-2.0)$ & $2.0(1.0-2.0)$ & 0.61 \\
\hline SGRQ total score & $44(32-62)$ & $43(27-58)$ & 0.06 \\
\hline \multicolumn{4}{|l|}{ Inhaled treatment \% } \\
\hline LAMA alone & 0.7 & 11.9 & $<0.0001$ \\
\hline LABA alone & 9.9 & 4.5 & 0.003 \\
\hline ICS alone & 9.6 & 2.1 & $<0.0001$ \\
\hline LABA+LAMA & 0.9 & 7 & $<0.0001$ \\
\hline LABA+ICS alone & 54.1 & 24 & $<0.0001$ \\
\hline$L A M A+L A B A+I C S$ & 2.4 & 32.5 & $<0.0001$ \\
\hline All LAMA & $4.0^{\S}$ & 53.0 & $<0.0001$ \\
\hline All LABA & 66.4 & 67.2 & 0.79 \\
\hline All ICS & 66.1 & 60.1 & 0.07 \\
\hline All ICS+LABA & 56.5 & 56.5 & 1 \\
\hline
\end{tabular}

Data are presented as median (interquartile range) unless otherwise stated. $F E V_{1}$ : forced expiratory volume in $1 \mathrm{~s}$; GOLD: Global Initiative for Chronic Obstructive Lung Disease; mMRC: modified Medical Research Council; SGRQ: St George's Respiratory Questionnaire; LAMA: long-acting muscarinic agent; LABA: long-acting $\beta_{2}$-agonist; ICS: inhaled corticosteroid. \#: May 2002 to May 31, 2006 (before LAMA release); ๆ: June 1, 2006 to June 20, 2012 (after LAMA release); ${ }^{+}$: during the year before inclusion; ${ }^{\S}$ : patients participating in clinical trials.

These findings are a potential cause of concern for two main reasons. Firstly, they suggest that, in the majority of patients, none of the currently available drug classes is able to provide sufficient relief of symptoms when used alone, even in mildly to moderately severe disease. Therefore, physicians tend to combine pharmacological classes in a high proportion of patients, although this might not translate into optimised benefit/risk/cost ratios for each prescribed drug. This underlines the need for new pharmacological approaches. Secondly, there is obviously an important need to clarify the respective roles and performances of drug classes that are currently available in COPD. Independent clinical studies should be performed to help identifying categories of patients more prone to respond to one treatment than to another (e.g. by comparing maximal bronchodilation to anti-inflammatory approaches, in well-defined patient groups).

In conclusion, the arrival of new pharmacological agents for COPD treatment appears to increase the proportion of patients of all severity stages receiving double or triple therapy, suggesting large unmet needs in terms of treatment effectiveness and strategy assessment.

- @ERSpublications

New agents for COPD treatment appear to increase overall treatment intensity in all severity categories http://ow.ly/BS6Wq

Nicolas Roche ${ }^{1}$, Gilles Jebrak ${ }^{2}$, Denis Caillaud ${ }^{3}$, Gaetan Deslée, Graziella Brinchault ${ }^{5}$, Pascal Chanez ${ }^{6}$, Isabelle Court-Fortune ${ }^{7}$, Roger Escamilla ${ }^{8}$, Pascale Nesme-Meyer', Christophe Pinet ${ }^{10}$, Philippe Carré ${ }^{11}$, Jean-Louis Paillasseur ${ }^{12}$, Thierry Perez ${ }^{13}$ and Pierre-Régis Burgel ${ }^{1}$, on behalf of the Initiatives BPCO scientific committee

${ }^{1}$ Service de Pneumologie, Hôpital Cochin, AP-HP and Université Paris Descartes (EA2511), Sorbonne Paris Cité, Paris, France. ${ }^{2}$ Service de Pneumologie, Hôpital Bichat, AP-HP, Paris, France. ${ }^{3}$ Service de Pneumologie, Hôpital Gabriel Montpied, CHU Clermont-Ferrand, Clermont-Ferrand, France. ${ }^{4}$ Service de Pneumologie, Hôpital Maison Blanche, CHU de Reims, Reims, France. ${ }^{5}$ Service de Pneumologie, Hôpital Pontchaillou, Rennes, France. ${ }^{6}$ Département des Maladies Respiratoires, AP-HM, Aix Marseille Université, Marseille, France. ${ }^{7}$ Service de Pneumologie, CHU Saint Etienne, Saint Etienne, France. ${ }^{8}$ Clinique des Voies Respiratoires, Hôpital Larrey, Toulouse, France. ${ }^{9}$ Service de Pneumologie, Hôpital de la Croix Rousse, Lyon, France. ${ }^{10}$ Polyclinique des Fleurs, Ollioules, France. ${ }^{11}$ Service de Pneumologie, Centre Hospitalier, Carcassonne, France. ${ }^{12}$ EFFI-STAT, Paris, France. ${ }^{13}$ Service de Pneumologie, Hôpital Calmette, Lille, France. 
Correspondence: Nicolas Roche, Pneumologie et Soins Intensifs Respiratoires, Groupe Hospitalier Cochin Broca HôtelDieu, Site HIA du Val de Grâce 4eC, 74 Bd de Port Royal, 75005 Paris, France. Email: nicolas.roche@cch.aphp.fr

Received: July 182014 | Accepted after revision: Aug 302014 | First published online: Oct 302014

Support statement: This study was supported by an unrestricted grant from Boehringer Ingelheim and Pfizer.

Conflict of interest: Disclosures can be found alongside the online version of this article at erj.ersjournals.com

\section{References}

1 Global Initiative for Chronic Obstructive Lung Disease. Global strategy for the diagnosis, management and prevention of chronic obstructive lung disease. www.goldcopd.org/uploads/users/files/GOLD_Report_2014_Jun11.pdf Date last updated: June 11, 2014.

2 Vogelmeier C, Hederer B, Glaab T, et al. Tiotropium versus salmeterol for the prevention of exacerbations of COPD. N Engl J Med 2011; 364: 1093-1103.

3 Calverley PM, Anderson JA, Celli B, et al. Salmeterol and fluticasone propionate and survival in chronic obstructive pulmonary disease. N Engl J Med 2007; 356: 775-789.

4 Karner C, Cates CJ. Combination inhaled steroid and long-acting $\beta_{2}$-agonist in addition to tiotropium versus tiotropium or combination alone for chronic obstructive pulmonary disease. Cochrane Database Syst Rev 2011; 3: CD008532.

5 Sharif R, Cuevas CR, Wang Y, et al. Guideline adherence in management of stable chronic obstructive pulmonary disease. Respir Med 2013; 107: 1046-1052.

6 Burgel PR, Deslée G, Jebrak G, et al. Real-life use of inhaled corticosteroids in COPD patients versus the GOLD proposals: a paradigm shift in GOLD 2011? Eur Respir J 2014; 43: 1201-1203.

7 Fitch K, Iwasaki K, Pyenson B, et al. Variation in adherence with Global Initiative for Chronic Obstructive Lung Disease (GOLD) drug therapy guidelines: a retrospective actuarial claims data analysis. Curr Med Res Opin 2011; 27: 1425-1429.

8 Jochmann A, Scherr A, Jochmann DC, et al. Impact of adherence to the GOLD guidelines on symptom prevalence, lung function decline and exacerbation rate in the Swiss COPD cohort. Swiss Med Wkly 2012; 142: w13567.

9 Asche CV, Leader S, Plauschinat C, et al. Adherence to current guidelines for chronic obstructive pulmonary disease (COPD) among patients treated with combination of long-acting bronchodilators or inhaled corticosteroids. Int J Chron Obstruct Pulmon Dis 2012; 7: 201-209.

10 Antón E. How and when to use inhaled corticosteroids in chronic obstructive pulmonary disease? Expert Rev Respir Med 2013; 7: 25-32.

11 De Backer W, Vos W, Van Holsbeke C, et al. The effect of roflumilast in addition to LABA/LAMA/ICS treatment in COPD patients. Eur Respir J 2014; 44: 527-529.

12 Page C, Cazzola M. Bifunctional drugs for the treatment of asthma and chronic obstructive pulmonary disease. Eur Respir J 2014; 44: 475-482.

13 Agustí A, de Teresa L, De Backer W, et al. A comparison of the efficacy and safety of once-daily fluticasone furoate/vilanterol with twice-daily fluticasone propionate/salmeterol in moderate to very severe COPD. Eur Respir J 2014; 43: 763-772.

14 Spagnolo P, Fabbri LM, Bush A. Long-term macrolide treatment for chronic respiratory disease. Eur Respir J 2013; 42: $239-251$.

\section{Volumetric and scintigraphic changes following endoscopic lung volume reduction}

To the Editor:

Bronchoscopic treatment of emphysema represents an emerging therapeutic modality for advanced emphysematous lung destruction in chronic obstructive pulmonary disease (COPD). Within the proposed techniques for endoscopic lung volume reduction (ELVR), a significant amount of experience exists for the placement of endobronchial valves (EBV) (Zephyr ${ }^{\circledast}$ valves; Pulmonx, Inc., Redwood City, CA, USA) targeting atelectasis of the treated, emphysematous lobe [1, 2]. However, post-procedural clinical 